\title{
Post-traumatic stress disorder and temporomandibular dysfunction: a review and clinical implications
}

\author{
Transtorno de estresse pós-traumático e disfunção temporomandibular: uma revisão e \\ implicações clínicas
}

Dyna Mara Araújo Oliveira Ferreira ${ }^{1}$, Camila Cristine de Oliveira Vaz², Juliana Stuginski-Barbosa', Paulo César Rodrigues Conti ${ }^{1}$

DOI 10.5935/2595-0118.20180012

\section{ABSTRACT}

BACKGROUND AND OBJECTIVES: Post-traumatic stress disorder is a disabling disorder that can be developed after a person has experienced or exposed to a traumatic event. The evidence shows the coexistence between post-traumatic stress disorder and chronic painful conditions as the temporomandibular dysfunction. This study aimed to review the literature to describe the coexistence relation between post-traumatic stress disorder and temporomandibular dysfunction.

CONTENTS: A non-systematic search was carried on the Pubmed, BVS and LILACS databases on studies evaluating the relationship between post-traumatic stress disorder and temporomandibular dysfunction. Clinical studies published in the last 10 years that presented a diagnostic criterion validated for temporomandibular dysfunction and the post-traumatic stress disorder were selected. Six studies were included in the review. The results showed that the post-traumatic stress disorder often occurs in patients with temporomandibular dysfunction and, at the same time, a higher prevalence of temporomandibular dysfunction is found in individuals with post-traumatic stress disorder. There is a trend for a larger connection between post-traumatic stress disorder and muscular pain than pain in the temporomandibular joint. The presence of post-traumatic stress disorder modulates the level of physical, psychological and behavioral involvement in individuals with temporomandibular dysfunction, and can predict the onset of this painful conditions.

CONCLUSION: The review shows a complex coexistence between post-traumatic stress disorder and painful temporomandibular dysfunction.

Keywords: Psychological trauma, Stress disorders, Temporomandibular joint dysfunction syndrome, Trauma.

\footnotetext{
1. Universidade de Săo Paulo, Faculdade de Odontologia de Bauru, Departamento de Prótese e Periodontia, Bauru, SP, Brasil.

2. Instituto de Ensino Odontológico de Bauru, Bauru, SP, Brasil.

Submitted in September 25, 2017.

Accepted for publication in January 15, 2018.

Conflict of interests: none - Sponsoring sources: none.

Correspondence to:

Al. Octávio Pinheiro Brisola, 9-75

17012-901 Bauru, SP, Brasil.

E-mail: dyna.mara@hotmail.com

(c) Sociedade Brasileira para o Estudo da Dor
}

\section{RESUMO}

JUSTIFICATIVA E OBJETIVOS: Transtorno de estresse póstraumático é um transtorno incapacitante que pode se desenvolver após exposiçấo ou testemunho de um evento traumático. Evidências demonstram a coexistência entre transtorno de estresse pós-traumático e condiçóes dolorosas crônicas como a disfunção temporomandibular. Este estudo teve como objetivo revisar a literatura para descrever a relaçáo de coexistência entre transtorno de estresse pós-traumático e disfunção temporomandibular.

CONTEÚDO: Foi realizada uma busca não sistemática nas bases de dados Pubmed, BVS e LILACS para estudos avaliando a relação entre transtorno de estresse pós-traumático e disfunçáo temporomandibular. Foram selecionados estudos clínicos publicados nos últimos 10 anos e que apresentassem critério diagnóstico validado para a disfunção temporomandibular e o transtorno de estresse pós-traumático. Seis trabalhos foram incluídos na revisão. Os resultados demonstraram que transtorno de estresse pós-traumático ocorre frequentemente em pacientes com disfunção temporomandibular e ao mesmo tempo, uma maior prevalência de disfunção temporomandibular é encontrada em indivíduos com transtorno de estresse pós-traumático. Há uma tendência indicando uma associação maior entre transtorno de estresse pós-traumático e dor muscular que dor na articulação temporomandibular. Presença do transtorno de estresse pós-traumático modula o nível de comprometimento físico, psicológico e comportamental em indivíduos com disfunção temporomandibular e pode predizer início desta condiçáo dolorosa. CONCLUSÃO: A revisão demonstra uma relação de coexistência complexa entre transtorno de estresse pós-traumático e disfunção temporomandibular dolorosa.

Descritores: Síndrome da disfunção da articulação temporomandibular, Transtornos de estresse pós-traumáticos, Trauma, Trauma psicológico.

\section{INTRODUCTION}

Temporomandibular disorder (TMD) comprises a group of musculoskeletal conditions involving the temporomandibular joint (TMJ), masticatory muscles and associated structures ${ }^{1}$. It is an important public health problem affecting 5 to $12 \%$ of the world population and represents the most common chronic painful condition in the orofacial region ${ }^{2,3}$. 
Post-traumatic stress disorder (PTSD) is a relatively common anxiety disorder and can be defined as a set of symptoms that manifests itself after exposure to a stressful or traumatic event ${ }^{4}$. According to the $5^{\text {th }}$ edition of the Diagnostic and Statistical Manual of Mental Disorders (DSM), PTSD diagnosis requires that the subject be exposed to a stressful event such as death, death threat, actual or possible serious injury, actual or possible sexual violence in the following forms: direct exposure, trauma testimony, knowledge that a family member or friend was exposed to trauma, or indirect exposure to trauma details $s^{4}$ PTSD is characterized by symptoms of negative and inopportune thoughts about trauma, nightmares, emotional distress, increased reactivity to stressful stimuli, and dodge/avoidance behavior ${ }^{4}$. These symptoms' persistence is what characterizes the pathological picture; i.e., PTSD reflects a failure of physiological and psychological adaptation, in which normal acute reactions to a stressor are not corrected over times.

Evidence shows that chronic painful TMD pictures often coexist with PTSD. Epidemiological studies have indicated that PTSD is more prevalent in TMD patients when compared to the general population ${ }^{6,7}$ and PTSD subjects also presented more TMD than subjects without the disorder ${ }^{8}$. In addition, the comorbidity relationship between TMD and PTSD may be a complicating factor for TMD handling, as it reduces the efficacy of commonly used therapeutic interventions?

The clinically observable relationship's reasons between TMD and PTSD are not fully understood, but some theoretical models have been proposed to explain the relationship between chronic pain and PTSD ${ }^{10-12}$. Among them, the mutual maintenance mode $^{10}{ }^{10}$ is the most widespread and suggests that components related to PTSD and painful condition exacerbate and maintain one another. Considering the negative impact of PTSD in the TMD patients handling, this study aims to describe the relationship of coexistence between TMD and PTSD, as well as the clinical implications involved in this relationship.

\section{CONTENTS}

A non-systematic literature search for studies on the relationship between PTSD and TMD published between 2007 and June 2017 was performed in Pubmed, BVS and LILACS databases. The search included the following keywords: temporomandibular joint; temporomandibular joint disorders; temporomandibular joint dysfunction syndrome; craniomandibular disorders combined with stress disorders, traumatic; stress disorders, posttraumatic; combat disorders and psychological trauma. The articles' titles and abstracts were evaluated to identify the inclusion criteria. There was no restriction for participants' age and gender. The papers should present primary results and written in Portuguese or English. The following criteria were adopted to verify the coexistence relationship between PTSD and TMD:

1. Cross-sectional, case-control, randomized clinical trial or cohort studies;

2. TMD diagnosis based on validated criteria $\left(\mathrm{RDC} / \mathrm{TMD}^{13}\right.$, DC/TMD ${ }^{14}$ or AAOP guidelines ${ }^{15}$ );

3. Medical PTSD diagnosis, or based on a structured questionnaire defined by DSM ${ }^{4,16}$.

\section{RESULTS}

The databases search resulted in 116 articles. After sorting the titles and abstracts, 12 articles were selected for a complete reading of the texts. From these, six meet the inclusion criteria ${ }^{6-8,17-19}$. One paper was excluded because it did not evaluate the relationship between TMD and PTSD ${ }^{20}$ and five because they did not use diagnostic criteria validated for TMD, only evaluating signs and symptoms of dysfunction in the studied population ${ }^{21-25}$. The flowchart with the article selection process is shown in figure 1 , and the information of the studies included in the review is shown in table 1 .

Table 1. Information of the included studies

\begin{tabular}{|c|c|c|}
\hline Authors & Study types & Studied population \\
\hline Bertoli et al. ${ }^{6}$ & Cross-sectional & $\begin{array}{l}445 \text { patients with painful TMD } \\
91 \% \text { women }\end{array}$ \\
\hline $\begin{array}{l}\text { Burris et } \\
\text { al. }{ }^{17}\end{array}$ & Cross-sectional & $\begin{array}{l}411 \text { patients with orofacial pain re- } \\
\text { porting traumatic life events prior to } \\
\text { pain } \\
100 \% \text { women }\end{array}$ \\
\hline
\end{tabular}

\section{Main results}

$46 \%$ reported at least one traumatic stressor event.

$12.6 \%$ with PTSD.

PTSD prevalence is higher in the muscle pain group (14.9\%) than in the joint pain group (9.9\%); although not statistically different. Positive association between PTSD and disability, psychological dysfunction, difficulty coping with pain and sleep problems.

23,6\% with PTSD.

PTSD was associated with greater severity of pain, daily interferences, psychological dysfunction, reduced levels of daily activity and sleep problems.

Porto et al. ${ }^{7}$ Cross-sectional 81 patients with myofascial pain $43.2 \%$ reported at least one traumatic stressor event. type TMD

$73 \%$ women

Weber et Cross-sectional 610 patients with TMD reporting al. ${ }^{18} \quad$ traumatic life events $85 \%$ women

Muhvi囚-Urek Case-control 50 war veterans with PTSD et al. ${ }^{8}$ 50 healthy subjects $100 \%$ men

Fillingim et Cohort $\quad 3,263$ healthy subjects monitored for

al. ${ }^{19} \quad 2.8$ years
$14.8 \%$ with PTSD.

PTSD predicts pain severity, psychological dysfunction, and interference in daily activities in TMD patients.

TMD prevalence was $48 \%$ in the veterans and $8 \%$ in the control group. The most common diagnosis was myofascial pain among veterans and disc displacement in the control group.

PTSD was associated with a higher incidence of painful TMD (risk ratio $=1.38$ ). 


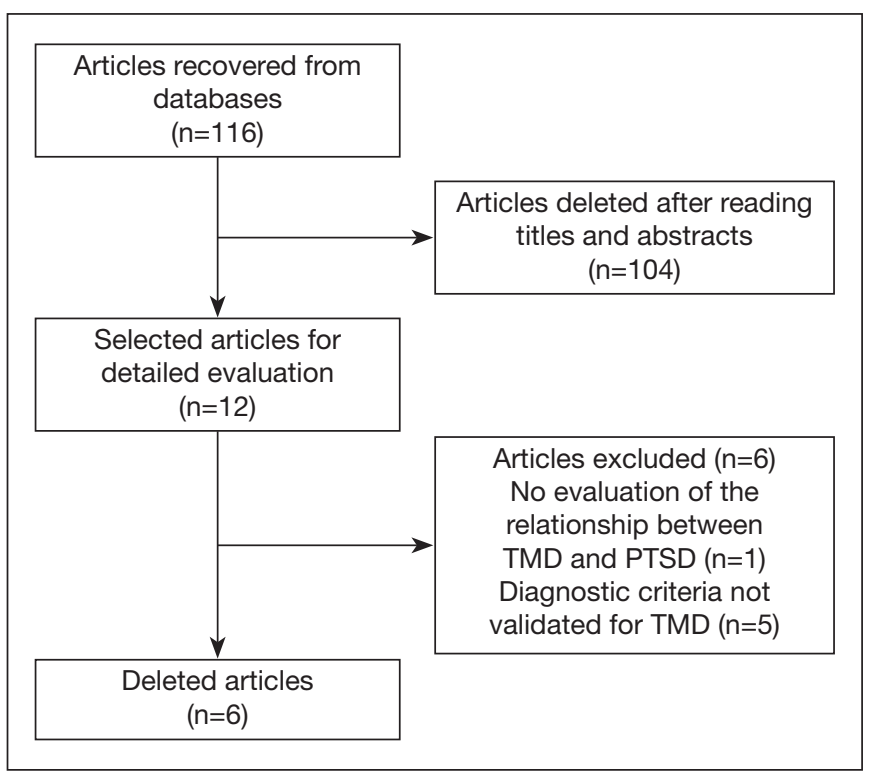

Figure 1. Study selection process flowchart

$\mathrm{TMD}=$ temporomandibular disorder; PTSD = post-traumatic stress disorder

The relationship between PTSD and TMD was investigated through cross-sectional, case-control, and cohort studies. Among TMD patients, 43 to $46 \%$ reported at least one traumatic stressor event ${ }^{6,7}$. PTSD prevalence in TMD patients ranged from 12.6 to $23.6 \%$ in the studies ${ }^{6,7,17}$. The sample of TMD patients was composed mostly of women, with an average age ranging from 37 to 47 years old. One paper evaluated only subjects with masticatory muscle myofascial pain ${ }^{7}$ and three studies investigated populations with painful muscle and joint $\mathrm{TMD}^{6,17,18}$. In these papers ${ }^{6,7,17,18}$ the participants were not formally diagnosed (medical diagnosis) with PTSD but had symptoms consistent with PTSD diagnosis identified by Post-Traumatic Stress Disorder Check List-Civilian (PCL-C) ${ }^{26}$, a structured questionnaire, developed according to the DSM, and validated to investigate the PTSD prevalence in epidemiological surveys.

Only one paper investigated the TMD prevalence in PTSD subjects ${ }^{8}$. TMD prevalence was $48 \%$ in PTSD subjects and $8 \%$ in healthy subjects. The most common TMD diagnosis was myofascial pain among PTSD subjects, while in the control group it was disc displacement. The PTSD population studied consisted of war veterans with an average age of 42 years and with medical PTSD diagnosis.

The positive association between PTSD symptoms and variables such as pain intensity, disability, psychological dysfunction, difficulties in coping with pain, interference with daily activities and sleep problems were found in three studies ${ }^{6,17,18}$.

Finally, a cohort study reported that PTSD predicted the incidence of painful TMD in healthy populations with a risk ratio of $1.38^{19}$.

\section{DISCUSSION}

The bidirectional relationship between PTSD and painful TMD is supported by studies evaluating the prevalence, inci- dence, and correlation between the two conditions. Approximately half of the TMD patients reported at least one lifethreatening traumatic event ${ }^{6,7}$ and 12,6 to $23,6 \%$ fulfilled the criteria for PTSD ${ }^{6,717}$. Epidemiological studies show that 30 to $90 \%$ of the population report a traumatic events history; however, the PTSD prevalence is less than $10 \%{ }^{27,28}$. Therefore, the included studies indicated a higher PTSD prevalence in TMD subjects than in the general population. These results corroborate a recently published systematic review demonstrating that there is sufficient evidence to confirm the association between PTSD and chronic painful conditions ${ }^{29}$. In addition, PTSD seems to be strongly associated with certain conditions of chronic pain in the craniofacial segment than other conditions. In a subgroup analysis, the PTSD prevalence was higher among subjects with a headache and facial pain (9 to 25\%) than in subjects with lumbar pain $(0.3 \text { to } 0.7 \%)^{29,30}$.

TMD patients reported traumatic stressors of different natures. Knowing that a family member or friend was injured or killed; experiencing automobile accidents and suffering from violent attacks were the most commonly reported traumatic experiences and of important personal significance for TMD patients ${ }^{17}$.

PTSD prevalence for different TMD subgroups was investigated by Bertoli et al. ${ }^{6}$. Although not statistically significant, the values indicated a higher PTSD prevalence in subjects with masticatory muscles pain when compared to TMJ pain. An explanation for these results is the greater psychological vulnerability found in subjects with myalgia. These patients present high levels of anxiety, depression, pain-related disability, and report a greater number of stressful events than subjects with arthralgia $^{31,32}$. Additional studies investigating the PTSD prevalence in subgroups of TMD patients are needed to elucidate this outcome.

From another perspective, the TMD prevalence is higher in PTSD subjects when compared to subjects without PTSD ${ }^{8}$. Studies of this nature are carried out mainly in at-risk populations for PTSD, such as war veterans or natural disasters victims. PTSD development after traumatic events is associated with increased risk of musculoskeletal pain and functional somatic syndromes (FSS) 33,34 .

In addition, subjects with both conditions, TMD and PTSD, presented greater pain intensity, psychological dysfunction, interference with daily activities, sleep problems and pain coping difficulties when compared to subjects without PTSD ${ }^{6,17,18}$.

These results may be reflective of changes in pain processing found in PTSD subjects.

A recent study with quantitative sensory tests demonstrated increased pain sensitivity (hyperalgesia) possibly related to processes of central sensitization in these subjects ${ }^{35}$. On the other hand, PTSD was associated with reduced sensitivity to noxious stimuli (hypoalgesia) ${ }^{36}$. This pattern type suggests preservation of the sensory pathways and absence of central sensitization and indicates that the pain perception in these patients is modulated centrally by emotional factors ${ }^{36}$. However, it is still uncertain whether alterations in pain processing are pre-existing risk factors for PTSD development or whether they are consequences of exposure to trauma and its neurobiological implications. 
A set of physiological and psychological processes is triggered when the human being experiences stressful or traumatic events. For many, these physiological changes return to normal once the stressor or trauma is ceased. However, the initial state of hyperexcitation may become chronic for some subjects. Chronic hyperexcitation leads to physiological stress system dysregulation and to the development of several changes.

Studies have demonstrated dysfunction in the hypothalamicpituitary-adrenal (HPA $)^{37}$ axis and abnormal activation patterns in frontal-limbic brain areas (prefrontal cortex, hippocampus, insula, and amygdala) in PTSD subjects ${ }^{38}$. In addition, the trauma experience may also affect the interpretation of a potentially threatening stimulus. This interpretation bias may then result in dodge behavior, catastrophic symptoms, and amplification of the disease state ${ }^{34}$.

Studies investigating the temporal relationship between TMD and PTSD are scarce in the literature and this review identified only one cohort study ${ }^{19}$. Fillingim et al. ${ }^{19}$ reported that the PTSD presence in healthy subjects predicts the risk for developing painful TMD (Risk Rate 1.38). This result corroborates with retrospective studies outcomes. A recent meta-analyzes has shown that exposure to traumatic life events such as physical, sexual, emotional abuse, war combat or PTSD diagnosis increases by 2.7 times the chance of a subject developing FSS such as TMD, fibromyalgia, generalized chronic pain, chronic fatigue syndrome and irritable bowel syndrome ${ }^{34}$. In addition, when trauma results in PTSD, the link between exposure to traumatic events and FSS becomes more pronounced. This illustrates the impact that PTSD development following trauma can have on health. While a person exposed to trauma may or may not have a long-term maladaptive response, a subject who develops PTSD will likely have several physiologi$\mathrm{cal}$, psychological, and behavioral consequences that may limit recovery and may result in the FSS development ${ }^{34}$. Further research with prospective methodologies to delineate a temporal relationship between PTSD and TMD and the factors that influence this relationship are necessary.

Understanding the reasons that explain the coexistence between PTSD and painful TMD is difficult due to overlapping symptoms. Both conditions share somatic hypervigilance, dodge behavior, high levels of fear and arousal to traumatic stimuli, suffering and dysregulation of the stress system ${ }^{28,39}$. Some theoretical models have been proposed to explain the relationship between chronic pain and PTSD ${ }^{10-12}$, although none presents significant empirical support. The mutual maintenance model proposed by Sharp and Harvey is the most widespread ${ }^{10}$. In this model, the cognitive, affective and behavioral components of chronic pain exacerbate and maintain PTSD; while the physiological, affective and behavioral components of PTSD exacerbate and maintain problems related to chronic pain. For example, pain in PTSD subjects can cause discomfort, increase stress, apathy and be a trigger to remember the trauma. On the other hand, remembering the trauma promotes hypervigilance behavior and dodge of activities related to pain that result in the pain experience amplification. The subject then engages in a vicious cycle where the PTSD symptoms and pain interact producing emotional distress and self-sustaining functional disability ${ }^{10}$.

\section{Clinical implications}

Psychiatric disorders related to traumatic events usually go unnoticed when evaluating TMD subjects. Considering the high PTSD prevalence in these patients, especially in cases of masticatory muscle myalgia, it is prudent to adopt screening instruments for PTSD, since there is a chance of this condition being present. Another implication is that treatments for chronic pain are time-consuming and require patient adherence. Subjects diagnosed with PTSD are three times more likely not to adhere to treatment ${ }^{40}$. In addition, individuals with painful TMD who report high levels of psychiatric symptoms make up a subgroup of patients for whom conventional treatments are ineffective? ${ }^{9}$. In such cases, effective interventions for both TMD and PTSD, including psychiatric and psychological therapies, should be considered in the treatment plan.

\section{CONCLUSION}

This review described a complex coexistence relationship between PTSD and painful TMD. PTSD frequently occurs in patients with TMD, and at the same time, a higher TMD prevalence is found in PTSD subjects. There is a trend indicating a greater relationship between PTSD and muscle pain than TMJ pain. PTSD presence modulates the level of physical, psychological and behavioral impairment in TMD subjects and can predict the onset of this painful condition.

\section{REFERENCES}

1. de Leeuw R, Klasser GD. Diagnosis and Management of TMDs. In: Orofacial Pain Guidelines for Assessment, Diagnosis, and Management. $5^{\text {th }}$ ed. Chicago: Quintessence; 2013. 127-85p.

2. Facial Pain. In: National Institute of Dental and Craniofacial Research. Disponíve em: http://www.nidcr.nih.gov/DataStatistics/FindDataByTopic/FacialPain/. Acesso em Julho de 2017.

3. Durham J, Shen J, Breckons M, Steele JG, Araujo-Soares V, Exley C, et al. Healthcare cost and impact of persistent orofacial pain: The DEEP Study Cohort. J Dent Res. 2016;95(10):1147-54

4. Post-Traumatic Stress Disorder. In: Diagnostic and Statistical Manual of Menta Disorders(DSM). 5th ed. 2013. Disponível em: https://www.ptsd.va.gov/professional/PTSD-overview/dsm5_criteria_ptsd.asp. Acesso em Julho de 2017.

5. Friedman MJ, Resick PA, Bryant RA, Brewin CR. Considering PTSD for DSM-5. Depress Anxiety. 2011;28(9):750-69.

6. Bertoli E, de Leeuw R, Schmidt JE, Okeson JP, Carlson CR. Prevalence and im pact of post-traumatic stress disorder symptoms in patients with masticatory muscle or temporomandibular joint pain: differences and similarities. J Orofac Pain. 2007;21(2):107-19.

7. Porto F, de Leeuw R, Evans DR, Carlson CR, Yepes JF, Branscum A, et al. Differences in psychosocial functioning and sleep quality between idiopathic continuous orofacial neuropathic pain patients and chronic masticatory muscle pain patients. J Orofac Pain. 2011;25(2):117-24.

8. Muhvić-Urek M, Uhac I, Vuksić-Mihaljević Z, Leović D, Blecić N, Kovac Z. Oral health status in war veterans with post-traumatic stress disorder. J Oral Rehabil. 2007;34(1):1-8.

9. Litt MD, Porto FB. Determinants of pain treatment response and nonresponse: identification of TMD patient subgroups. J Pain. 2013;14(11):1502-13.

10. Sharp TJ, Harvey AG. Chronic pain and posttraumatic stress disorder: mutual maintenance? Clin Psychol Rev. 2001;21(6):857-77.

11. Asmundson GJ, Coons MJ, Taylor S, Katz J. PTSD and the experience of pain: Research and clinical implications of shared vulnerability and mutual maintenance models. Can J Psychiatry. 2002;47(10):930-7.

12. Scioli-Salter ER, Forman DE, Otis JD, Gregor K, Valovski I, Rasmusson AM. The shared neuroanatomy and neurobiology of comorbid chronic pain and PTSD: therapeutic implications. Clin J Pain. 2015;31(4):363-74.

13. Dworkin SF, LeResche L. Research diagnostic criteria for temporomandibular disorders: review, criteria, examinations and specifications, critique. J Craniomandib Disord. 1992;6(4):301-55.

14. Schiffman E, Ohrbach R, Truelove E, Look J, Anderson G, Goulet JP, et al. Diag- 
nostic Criteria for Temporomandibular Disorders (DC/TMD) for Clinical and Research Applications: recommendations of the International RDC/TMD Consortium Network and Orofacial Pain Special Interest Group. J Oral Facial Pain Headache. 2014;28(1):6-27.

15. de Leeuw R, Klasser GD. Orofacial Pain: Guidelines for Assessment, Diagnosis and Management. Hanover Park, IL: Quintessence Publishing Company; 2013.

16. American Psychiatric Association. Diagnostic and Statistical Manual of Mental Disorders (DSM), $4^{\text {th }}$ ed. Washington, 2000.

17. Burris JL, Cyders MA, de Leeuw R, Smith GT, Carlson CR. Posttraumatic stress disorder symptoms and chronic orofacial pain: an empirical examination of the mutual maintenance model. J Orofac Pain. 2009;23(3):243-52.

18. Weber T, Boggero IA, Carlson CR, Bertoli E, Okeson JP, de Leeuw R. Smoking and posttraumatic stress disorder symptomatology in orofacial pain. J Dent Res. 2016;95(10):1161-8.

19. Fillingim RB, Ohrbach R, Greenspan JD, Knott C, Diatchenko L, Dubner R, et al. Psychological factors associated with development of TMD: the OPPERA prospective cohort study. J Pain. 2013;14(12 Suppl):T75-90.

20. Wiener RC. Oral health perception in veterans with self-identified disabilities: National Survey of Veterans, 2010. J Public Health Dent. 2015;75(3):245-52.

21. Schur EA, Afari N, Furberg H, Olarte M, Goldberg J, Sullivan PF, Buchwald D. Feeling bad in more ways than one: comorbidity patterns of medically unexplained and psychiatric conditions. J Gen Intern Med. 2007;22(6):818-21.

22. Uhac I, Tariba P, Kovac Z, Simonić-Kocijan S, Lajnert V, Mesić VF, et al. Masticatory muscle and temporomandibular joint pain in Croatian war veterans with posttraumatic stress disorder. Coll Antropol. 2011;35(4):1161-6.

23. Mottaghi A, Zamani E. Temporomandibular joint health status in war veterans with post-traumatic stress disorder. J Educ Health Promot. 2014;23;3:60.

24. Ajanović M, Tosum S, Kamber-Ćesir A, Đonlagić A, Kazazić L, Hamzić A. Prevalence of signs and symptoms of temporomandibular disorder in patients with posttraumatic stress disorder. Pesq Bras Odontoped Clin Integr. 2014;14(1):43-8.

25. Afari N, Wen Y, Buchwald D, Goldberg J, Plesh O. Are post-traumatic stress disorder symptoms and temporomandibular pain associated? Findings from a community-based twin registry. J Orofac Pain. 2008;22(1):41-9.

26. Weathers FW, Huska JA, Keane TM. PCL-C for DSM-IV. Boston: National Center for PTSD - Behavioral Science Division; 1991.

27. Kessler RC, Berglund P, Demler O, Jin R, Merikangas KR, Walters EE. Lifetime prevalence and age-of-onset distributions of DSM-IV Disorders in the National Comorbidity Survey Replication. Arch Gen Psychiatry. 2005;62(6):593-602.
28. Kilpatrick DG, Resnick HS, Milanak ME, Miller MW, Keyes KM, Friedman MJ National estimates of exposure to traumatic events and PTSD prevalence using DSM -IV and DSM-V criteria. J Trauma Stress. 2013;26(5):537-47.

29. Fishbain DA, Pulikal A, Lewis JE, Gao J. Chronic pain types differ in their reported prevalence of post-traumatic stress disorder (PTSD) and there is consistent evidence that chronic pain is associated with PTSD: an evidence-based structured systematic review. Pain Med. 2017;1;18(4):711-35.

30. Siqveland J, Hussain A, Lindstrøm JC, Ruud T, Hauff E. Prevalence of posttraumatic stress disorder in persons with chronic pain: a meta-analysis. Front Psychiatry. 2017;14;8:164

31. Lindroth JE, Schmidt JE, Carlson CR. A comparison between masticatory muscle pain patients and intracapsular pain patients on behavioral and psychosocial domains. J Orofac Pain. 2002;16(4):277-83.

32. De Leeuw R, Bertoli E, Schmidt JE, Carlson CR. Prevalence of traumatic stressors in patients with temporomandibular disorders. J Oral Maxillofac Surg. 2005;63(1):42-50.

33. Wahlström L, Michélsen H, Schulman A, Backheden M, Keskinen-Rosenqvist R. Longitudinal course of physical and psychological symptoms after a natural disaster. Eur J Psychotraumatol. 2013;27;4.

34. Afari N, Ahumada SM, Wright LJ, Mostoufi S, Golnari G, Reis V, et al. Psychological trauma and functional somatic syndromes: a systematic review and meta-analysis. Psychosom Med. 2014;76(1):2-11.

35. Moeller-Bertram T, Strigo IA, Simmons AN, Schilling JM, Patel P, Baker DG. Evidence for acute central sensitization to prolonged experimental pain in posttraumatic stress disorder. Pain Med. 2014;15(5):762-71.

36. Mostoufi S, Godfrey KM, Ahumada SM, Hossain N, Song T, Wright LJ, et al. Pain sensitivity in posttraumatic stress disorder and other anxiety disorders: a preliminary case control study. Ann Gen Psychiatry. 2014;18;13(1):31.

37. Jones T, Moller MD. Implications of hypothalamic-pituitary-adrenal axis functioning in posttraumatic stress disorder. J Am Psychiatr Nurses Assoc. 2011;17(6):393-403.

38. Geuze E, Westenberg HG, Jochims A, de Kloet CS, Bohus M, Vermetten E, et al. Altered pain processing in veterans with posttraumatic stress disorder. Arch Gen Psychiatry. 2007;64(1):76-85

39. Rollman GB, Gillespie JM. The role of psychosocial factors in temporomandibular disorders. Curr Rev Pain. 2000;4(1):71-81.

40. Kronish IM, Edmondson D, Goldfinger JZ, Fei K, Horowitz CR. Posttraumatic stres disorder and adherence to medications in survivors of strokes and transient ischemic attacks. Stroke. 2012;43(8):2192-7. 